JURNAL MATEMATIKA. STATISTIKA \& KOMPUTASI

https-//journal unhas.acid/indexphp/jmsk/index

Vol. 17, No. 2, 267-279, January, 2021

DOI: 10.20956/jmsk.v17i2.11984

\title{
Stability Analysis of Divorce Dynamics Models
}

\author{
Syamsir $^{1^{*}}$, Syamsuddin Toaha $^{2^{*}}$, Kasbawati $^{3^{*}}$
}

\begin{abstract}
This article examines the mathematical model of divorce. This model consists of four population classes, namely the Married class (M), the population class who experiences separation of separated beds (S), the population class who is divorced by Divorce (D), and the population class who experiences depression or stress due to divorce Hardship (H). This study focuses on the stability analysis of divorce-free and endemic equilibrium points. Local stability was analyzed using linearization and eigenvalues methods. In addition, the basic reproduction number $\mathrm{R}_{0}$ is provided via the next generation matrix method. The existence and stability of the equilibrium point are determined from $R_{0}$. The results showed that the rate of interaction between population $\mathrm{M}$ and populations other than $\mathrm{H}$ is very influential on efforts to minimize divorce. Divorce can be minimized when the transmission rate is reduced to $\mathrm{R}_{0}<1$. Reducing the transmission rate and increasing the rate of transfer from split bed class to married class can turn divorce endemic cases into non-endemic cases. A numerical simulation is given to confirm the analysis results.
\end{abstract}

Keywords: Divorce Dynamics, Mathematical Model, Equilibrium Point, Stability Analysis, basic reproduction numbers.

\section{Introduction}

In a marriage, everyone wants a happy, eternal, and prosperous home life, in accordance with the objectives of marriage as stated in Law No.1 of 1974 ([1,9]). However, not everyone can form a family that they aspire to, this is due to divorce, both death divorce, divorce talaq, and divorce based on the judge's decision [1]. The problem of the dynamics of the divorce epidemic is one of the most familiar problems in society. Several previous studies have modeled problems related to the dynamics of this divorce [15]. For example, the mathematical model of divorce dynamics developed by Patience Pokuaa Gambrah, et al [6], which examines the impact of counseling in divorce cases. Then the research conducted by Patience Pokuaa Gambrah and Yvonne Adzadu [7] divided the mathematical model into 3 compartments, namely marriage $(\mathrm{M})$, separated $(\mathrm{S})$, Divorced (D). In this study, the researchers drew a conclusion that the divorce epidemic can not

* Program Studi Magister Matematika, FMIPA-UNHAS

Email: ${ }^{1}$ syamsir.cagur94@gmail.com, ${ }^{2}$ syamsuddint@yahoo.com, ${ }^{3}$ kasbawati@gmail.com (c) (i) \&

This work is licensed under a Creative Commons Attribution-NonCommercial 4.0 International License 


\section{Syamsir, Syamsuddin Toaha, Kasbawati Jurnal Matematika, Statistika \& Komputasi}

only be controlled by reducing the level of contact between marriage and divorce but also increasing the number of marriages that go into separation and educating themselves from divorce which can be useful in fighting the epidemic.

In this research, researchers will make modifications by combining the two models mentioned above and adding some controls to minimize the occurrence of divorce. Researchers will examine the dynamics of divorce with optimal control.

\section{Divorce Dynamics Model}

The development of the model in this study is an amalgamation of the dynamics of divorce according to Patience Pokuaa Gambrah, et al [6] and Patience Pokuaa Gambrah and Yvonne Adzadu [7] then resolved with optimal control theory ([5, 13,14]). The results of the model development obtained are four compartments, namely Marriage (M), Separated (S), Divorce (D), and Hardship (H). The development of this model adds family role factors or family interference and external factors (Judges) in an effort to suppress divorce.

The assumptions are formed as follows:

1. New recruits who enter the Marriage class (M) with a constant rate of $\Lambda$.

2. Interactions between $M$ with other populations except Hardship $(H)$ cause individuals in the M population to move to the Divorce (D) or Separated (S) population.

3. Individuals in population $\mathrm{S}$ are susceptible to transferring to population $\mathrm{D}$ at a rate of $\delta \mathrm{S}$.

4. Population $\mathrm{D}$ is prone to depression or stress and moves to population $\mathrm{H}$ at a rate of $\mathrm{D}$.

5. Individuals in the population $\mathrm{S}, \mathrm{D}$, and $\mathrm{H}$ are assumed to be able to remarry.

6. Each compartment of the 4 classes in the population has a death rate with a constant rate of $\mu$. Schematic diagram of the 4 classes in the model with the assumptions above as follows.

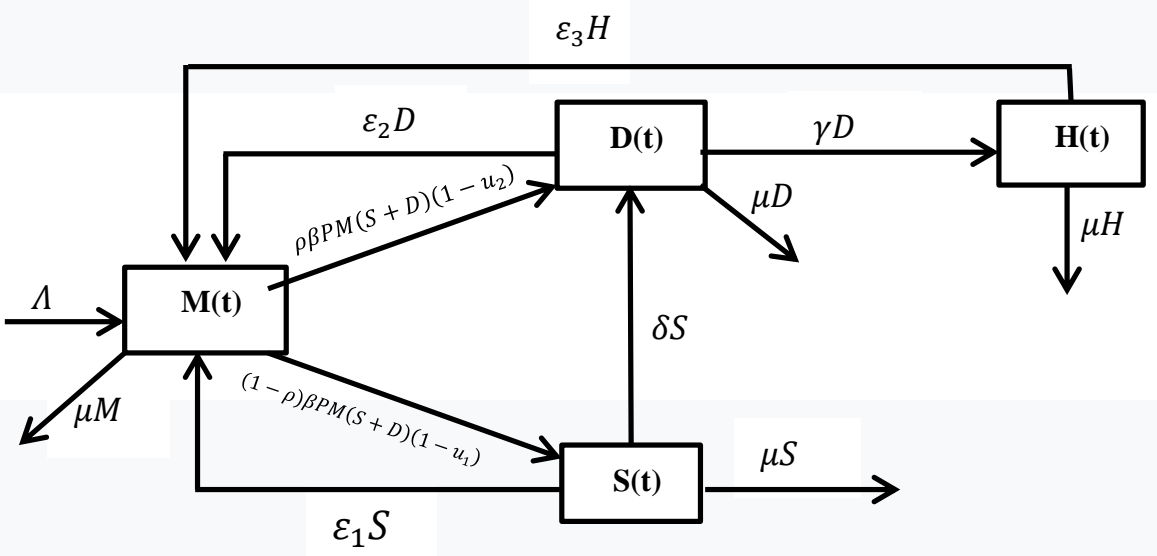

Figure 2.1. Compartment Diagram for Divorce Dynamics Mathematical Model

From the compartment diagram of the model, the following system of differential equations is obtained: 
$\frac{d M}{d t}=\Lambda+\varepsilon_{2} D+\varepsilon_{1} S+\varepsilon_{3} H-\rho \beta P M(S+D)\left(1-u_{2}\right)-(1-\rho) \beta P M(S+D)\left(1-u_{1}\right)-\mu M$
$\frac{d S}{d t}=(1-\rho) \beta P M(S+D)\left(1-u_{1}\right)-\varepsilon_{1} S-\delta S-\mu S$
$\frac{d D}{d t}=\rho \beta P M(S+D)\left(1-u_{2}\right)+\delta S-\varepsilon_{2} D-\gamma D-\mu D$
$\frac{d H}{d t}=\gamma D-\varepsilon_{3} H-\mu H$

With the total population

$N=M+S+D+H$

is assumed that the initial conditions of the system meet:

$M(0)=M_{0}, S(0)=S_{0}, D(0)=D_{0}, H(0)=H_{0}$,

With $M_{0}, S_{0}, D_{0}, H_{0} \geq 0$

From system (4.1) can be obtained:

$$
\begin{gathered}
\frac{d N}{d t}=\frac{d M}{d t}+\frac{d S}{d t}+\frac{d D}{d t}+\frac{d H}{d t} \\
\begin{aligned}
\frac{d N}{d t}=\Lambda+\varepsilon_{2} D+\varepsilon_{1} S+\varepsilon_{3} H-\rho \beta P M(S+D)\left(1-u_{2}\right)-(1-\rho) \beta P M(S+D)\left(1-u_{1}\right)-\mu M \\
\quad+(1-\rho) \beta P M(S+D)\left(1-u_{1}\right)-\varepsilon_{1} S-\delta S-\mu S+\rho \beta P M(S+D)\left(1-u_{2}\right)
\end{aligned} \\
\quad+\delta S-\varepsilon_{2} D-\gamma D-\mu D+\gamma D-\varepsilon_{3} H-\mu H
\end{gathered}
$$

The description of the variables and parameters used is described in the following table.

Table 2.1 List of Variables and Parameters of Divorce Dynamics Model

\begin{tabular}{llcl}
\hline Symbol & \multicolumn{1}{c}{ Desription } & Terms & Unit \\
\hline $\boldsymbol{N}(\boldsymbol{t})$ & Total Population at one time t. & $N(t)>0$ & Person \\
$\boldsymbol{M}(\boldsymbol{t})$ & Number of people who are married at one time t. & $M(t) \geq 0$ & Person \\
$\boldsymbol{S}(\boldsymbol{t})$ & Number of people with split-bed status at a time t. & $S(t) \geq 0$ & Person \\
$\boldsymbol{D}(\boldsymbol{t})$ & Number of people who are divorced at one time t. & $D(t) \geq 0$ & Person \\
$\boldsymbol{H}(\boldsymbol{t})$ & $\begin{array}{l}\text { Number of people who are divorced and experience } \\
\text { depression or stress at any one time t. }\end{array}$ & $H(t) \geq 0$ & Person \\
\hline
\end{tabular}




\section{Syamsir, Syamsuddin Toaha, Kasbawati Jurnal Matematika, Statistika E Komputasi}

\begin{tabular}{|c|c|c|c|}
\hline$\Lambda$ & $\begin{array}{l}\text { The level of input of individuals who are prone to } \\
\text { divorce. }\end{array}$ & $\Lambda>0$ & Person/year \\
\hline $\boldsymbol{\beta}$ & $\begin{array}{l}\text { The average interaction between } \mathrm{M} \text { and individuals } \\
\text { other than } \mathrm{H} \text {. }\end{array}$ & $\beta>0$ & $\begin{array}{l}1 /(\text { time } \mathrm{x} \\
\text { person })\end{array}$ \\
\hline$\delta$ & The rate of people divorcing after separation & $\delta>0$ & 1/year \\
\hline$\gamma$ & $\begin{array}{l}\text { The rate at which people experience depression or } \\
\text { stress after divorce }\end{array}$ & $\gamma>0$ & 1/year \\
\hline$\varepsilon_{1}$ & $\begin{array}{l}\text { The rate of people getting married again after } \\
\text { divorcing }\end{array}$ & $\varepsilon_{1}>0$ & 1/year \\
\hline$\varepsilon_{2}$ & $\begin{array}{l}\text { The rate at which people return to married status } \\
\text { after separation }\end{array}$ & $\varepsilon_{2}>0$ & 1/year \\
\hline$\varepsilon_{3}$ & $\begin{array}{l}\text { The rate at which people return to marriage after } \\
\text { experiencing depression or stress }\end{array}$ & $\varepsilon_{3}>0$ & 1/year \\
\hline$\rho$ & The proportion of $\mathrm{M}$ who were divorced & $\rho \geq 0$ & Person/year \\
\hline $\begin{array}{l}(1 \\
-\rho)\end{array}$ & The proportion of the number of M separated beds & $(1-\rho) \geq 0$ & Person/year \\
\hline $\boldsymbol{P}$ & $\begin{array}{l}\text { Chances of successful interaction between } \mathrm{M}(\mathrm{t}) \text { and } \\
\text { other populations except } \mathrm{H}(\mathrm{t})\end{array}$ & $0<P<1$ & - \\
\hline$\mu M$ & $\begin{array}{l}\text { The rate at which the amount of } \mathrm{M} \text { comes out } \\
\text { naturally }\end{array}$ & $\mu M \geq 0$ & $1 /$ year \\
\hline$\mu S$ & $\begin{array}{l}\text { The rate at which the amount of } \mathrm{S} \text { comes out } \\
\text { naturally }\end{array}$ & $\mu S \geq 0$ & 1/year \\
\hline$\mu D$ & $\begin{array}{l}\text { The rate at which the amount of D comes out } \\
\text { naturally }\end{array}$ & $\mu D \geq 0$ & 1/year \\
\hline$\mu H$ & $\begin{array}{l}\text { The rate at which the amount of } \mathrm{H} \text { comes out } \\
\text { naturally }\end{array}$ & $\mu H \geq 0$ & 1/year \\
\hline$u_{1}$ & $\begin{array}{l}\text { The proportion of individuals who are spared from } \\
\text { being separated from their beds is due to family } \\
\text { interference }\end{array}$ & $0 \leq u_{1} \leq 1$ & - \\
\hline$u_{2}$ & $\begin{array}{l}\text { Proportion of individuals who have avoided divorce } \\
\text { due to external parties (Judges) }\end{array}$ & $0 \leq u_{2} \leq 1$ & - \\
\hline
\end{tabular}

\section{The point of equilibrium and stability is divorce-free and endemic}

The divorce dynamics model in model (2.1) can be found for its equilibrium point if it meets $\frac{d M}{d t}=\frac{d S}{d t}=\frac{d D}{d t}=\frac{d H}{d t}=0([2,3,5,13])$. Based on these requirements, system (2.1) is obtained: $\Lambda+\varepsilon_{2} D+\varepsilon_{1} S+\varepsilon_{3} H-\rho \beta P M(S+D)\left(1-u_{2}\right)-(1-\rho) \beta P M(S+D)\left(1-u_{1}\right)-\mu M=0$ 


\section{Syamsir, Syamsuddin Toaha, Kasbawati Jurnal Matematika, Statistika \& Komputasi}

$$
\begin{aligned}
& (1-\rho) \beta P M(S+D)\left(1-u_{1}\right)-\varepsilon_{1} S-\delta S-\mu S=0 \\
& \rho \beta P M(S+D)\left(1-u_{2}\right)+\delta S-\varepsilon_{2} D-\gamma D-\mu D=0 \\
& \gamma D-\varepsilon_{3} H-\mu H=0
\end{aligned}
$$

The divorce-free equilibrium point is a condition where there is no divorce problem in a population or the number of divorced individuals is zero [12]. The point of divorce-free equilibrium is expressed in $E^{0}=\left(M^{0}, S^{0}, D^{0}, H^{0}\right)$ by assuming $S^{0}=D^{0}=0$. Thus from system (3), the divorce-free equilibrium point is obtained $E^{0}=\left(M^{0}, S^{0}, D^{0}, H^{0}\right)=\left(\frac{\Lambda}{\mu}, 0,0,0\right)$.

The equilibrium point of a divorce or endemic occurs when divorce is still occurring. Thus, endemic occurs when system (1) is stable but all compartments are always positive i.e. $M \neq$ $0, S \neq 0, D \neq 0$, and $H \neq 0$ or can be expressed in the form $E^{*}=\left(M^{*}, S^{*}, D^{*}, H^{*}\right)$ where $M^{*} \neq 0, S^{*} \neq 0, D^{*} \neq 0$ and $H^{*} \neq 0$.

\section{Basic Reproduction Numbers}

In epidemiology, the rate of spread of an infectious disease is usually measured by a value called the basic reproduction number $\left(R_{0}\right)([4,8,13])$.. In this case in order to be free from divorce, it must be set $R_{0}<1[10,11]$. In this case each divorced individual can only affect on average less than one new individual, so that in the end the divorce will be zero. Meanwhile, if $R_{0}>1$, then each individual who is divorced can cause or affect on average more than one new individual, so that in the end there will be an epidemic.

To find $R_{0}$, because what you want to control is the population that causes divorce, only models $S$ and $D$ are needed in equation (2.1), namely:

$$
\begin{aligned}
& \frac{d D}{d t}=\rho \beta P M(S+D)\left(1-u_{2}\right)+\delta S-\varepsilon_{2} D-\gamma D-\mu D \\
& \frac{d H}{d t}=\gamma D-\varepsilon_{3} H-\mu H
\end{aligned}
$$

From this equation, which causes an increase in divorce cases, namely $\rho \beta P M(S+D)+\delta S$ which can be considered as $\mathcal{F}_{i}(x)$. Whereas the rest is given as $\mathcal{V}_{i}(x)$ and negated, so that $\mathcal{F}_{i}(x)$. and $\mathcal{V}_{i}(x)$ are obtained as follows:

$$
\begin{gathered}
\mathcal{F}_{i}(x)=\left(\begin{array}{c}
\rho \beta P M(S+D)\left(1-u_{2}\right)+\delta S \\
0
\end{array}\right) \\
\mathcal{V}_{i}(x)=\left(\begin{array}{c}
\varepsilon_{2} D+\gamma D+\mu D \\
-\gamma D+\varepsilon_{3} H+\mu H
\end{array}\right)
\end{gathered}
$$

Furthermore, we obtain the $\mathrm{F}$ and $\mathrm{V}$ matrices substituted by the divorce-free equilibrium point $E^{0}=\left(M^{0}, S^{0}, D^{0}, H^{0}\right)=\left(\frac{\Lambda}{\mu}, 0,0,0\right)$

with the following results:

$$
F=\frac{\partial \mathcal{F}_{i}\left(E^{0}\right)}{\partial(D, H)}=\left(\begin{array}{ll}
\frac{\partial F_{1}}{\partial D} & \frac{\partial F_{1}}{\partial H} \\
\frac{\partial F_{2}}{\partial D} & \frac{\partial F_{2}}{\partial H}
\end{array}\right)=\left(\begin{array}{cc}
\rho \beta P M\left(1-u_{2}\right) & 0 \\
0 & 0
\end{array}\right)=\left(\begin{array}{cc}
\frac{\rho \beta P \Lambda\left(1-u_{2}\right)}{\mu} & 0 \\
0 & 0
\end{array}\right)
$$




\section{Syamsir, Syamsuddin Toaha, Kasbawati Jurnal Matematika, Statistika \& Komputasi}

$$
V=\frac{\partial \mathcal{V}_{i}\left(E^{0}\right)}{\partial(D, H)}=\left(\begin{array}{ll}
\frac{\partial V_{1}}{\partial D} & \frac{\partial V_{1}}{\partial H} \\
\frac{\partial V_{2}}{\partial D} & \frac{\partial V_{2}}{\partial H}
\end{array}\right)=\left(\begin{array}{cc}
\varepsilon_{2}+\gamma+\mu & 0 \\
-\gamma & \varepsilon_{3}+\mu
\end{array}\right)
$$

Next will be determined the inverse of the matrix $V$.

$$
\begin{aligned}
V^{-1} & =\frac{1}{\left(\varepsilon_{2}+\gamma+\mu\right)\left(\varepsilon_{3}+\mu\right)}\left(\begin{array}{cc}
\varepsilon_{3}+\mu & 0 \\
\gamma & \varepsilon_{2}+\gamma+\mu
\end{array}\right) \\
& =\left(\begin{array}{cc}
\frac{1}{\left(\varepsilon_{2}+\gamma+\mu\right)} & 0 \\
\frac{\gamma}{\left(\varepsilon_{2}+\gamma+\mu\right)\left(\varepsilon_{3}+\mu\right)} & \frac{1}{\left(\varepsilon_{3}+\mu\right)}
\end{array}\right)
\end{aligned}
$$

So that the basic reproduction value is obtained by multiplying the $F$ matrix by the inverse matrix $V$ as follows:

$$
\begin{gathered}
F V^{-1}=\left(\begin{array}{cc}
\frac{\rho \beta P \Lambda\left(1-u_{2}\right)}{\mu} & 0 \\
0 & 0
\end{array}\right)\left(\begin{array}{cc}
\frac{1}{\left(\varepsilon_{2}+\gamma+\mu\right)} & 0 \\
\frac{\gamma}{\left(\varepsilon_{2}+\gamma+\mu\right)\left(\varepsilon_{3}+\mu\right)} & \frac{1}{\left(\varepsilon_{3}+\mu\right)}
\end{array}\right) \\
=\left(\begin{array}{cc}
\frac{\rho \beta P \Lambda\left(1-u_{2}\right)}{\mu\left(\varepsilon_{2}+\gamma+\mu\right)} & 0 \\
0 & 0
\end{array}\right)
\end{gathered}
$$

Using the characteristic equation $\operatorname{det}\left(\lambda I-F V^{-1}\right)=0$, we get:

$$
\operatorname{det}\left(\begin{array}{cc}
\lambda-\frac{\rho \beta P \Lambda\left(1-u_{2}\right)}{\mu\left(\varepsilon_{2}+\gamma+\mu\right)} & 0 \\
0 & \lambda
\end{array}\right)=0
$$

or

$$
\lambda\left(\lambda-\frac{\rho \beta P \Lambda\left(1-u_{2}\right)}{\mu\left(\varepsilon_{2}+\gamma+\mu\right)}\right)=0
$$

which has a solution:

$$
\begin{gathered}
\lambda_{1}=0 \\
\lambda_{2}=\frac{\rho \beta P \Lambda\left(1-u_{2}\right)}{\mu\left(\varepsilon_{2}+\gamma+\mu\right)}
\end{gathered}
$$

Because the value of the basic reproduction number is obtained from the spectral radius or the largest value of the eigenvalues, the basic reproduction number for the system of equations above is

$$
R_{0}=\frac{\rho \beta P \Lambda\left(1-u_{2}\right)}{\mu\left(\varepsilon_{2}+\gamma+\mu\right)}
$$

with $\mu\left(\varepsilon_{2}+\gamma+\mu\right) \neq 0$ 


\section{Syamsir, Syamsuddin Toaha, Kasbawati Jurnal Matematika, Statistika \& Komputasi}

$R_{0}<1$ happens when $\rho \beta P \Lambda\left(1-u_{2}\right)<\mu\left(\varepsilon_{2}+\gamma+\mu\right)$ while $R_{0}>1$ happens when $\rho \beta P \Lambda(1-$ $\left.u_{2}\right)>\mu\left(\varepsilon_{2}+\gamma+\mu\right)$. Based on the results obtained for $R_{0}$, to make $R_{0}<1$, the denominator must be greater than the numerator. Mortality due to natural factors $(\mu)$ and the rate of depression or stress after divorce $(\gamma)$ cannot be increased. Therefore what needs to be done is to increase the number of individuals who return to their married status after separating $\left(\varepsilon_{2}\right)$. In addition, the mean interactions of $M$ with other individuals except $H(\beta)$ and the proportion of M divorced $(\rho)$ must also be derived. Whereas (P) is the chance of successful interaction between $\mathrm{M}$ and other populations except $\mathrm{H}$. Thus the divorce rate will be reduced. So it can be said, from this analysis it will be known that the most influential parameters of all the parameters in the divorce dynamic model are the parameters $\beta, \rho$, and $\varepsilon_{2}$. Suppose $\mu=0.003, \gamma=0.56, \rho=0.03, P=1$, and $\Lambda=0.08$, then the relationship between the average interaction of $M$ with individuals other than $H(\beta)$ to the rate of remarriage after parting $\left(\varepsilon_{2}\right)$ is illustrated in Figure 2 below.

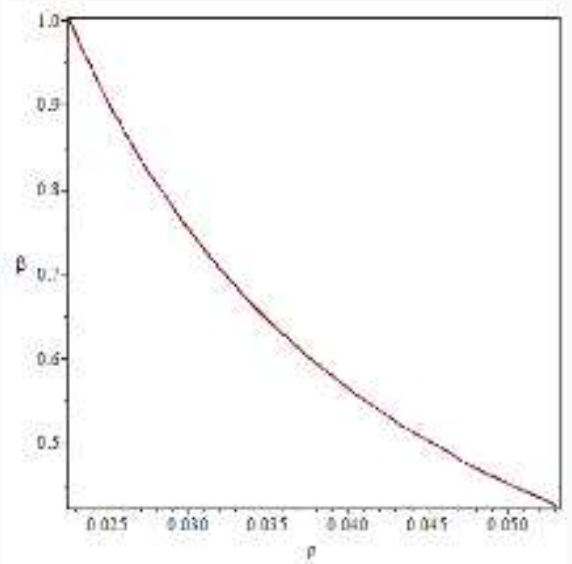

Figure 4.1. The relationship between the functions of $\beta$ and $\varepsilon_{2}$ when $R_{0}=1$

\section{Numerical Simulation}

Simulations are given to provide a geometric picture related to the results of the analysis that has been carried out. Simulations are made using the Maple 18 program and carried out by providing values for each parameter according to the condition $R_{0}$.

\section{a. Simulation for $\boldsymbol{R}_{\mathbf{0}}>\mathbf{1}$}

Based on the given model (2.2), and the values adopted from [6] and [7] and with a slight modification for the simulation are given $\mu=0.03, \beta=0.08, \rho=0.052, \gamma=0.00001, \delta=0.00001$, $\varepsilon_{1}=0.99, \varepsilon_{2}=0.28, \varepsilon_{3}=0.001, \mathrm{P}=0.021, u_{1}=0.9999$, and $u_{2}=0$. With this parameter value, the divorce-free equilibrium point is obtained $E^{0}=\left(M^{0}, S^{0}, D^{0}, H^{0}\right)=(4333,0,0,0)$, while the equilibrium point is endemic $E^{*}=\left(M^{*}, S^{*}, D^{*}, H^{*}\right)=(3546.68,0.4355,785.960,0.2535)$, and $R_{0}=1.221121899$. The eigenvalues associated with the divorce-free equilibrium point are $\{-0.0300,0.0310,0.0687,-1.0195\}$. There is a positive eigenvalue at the divorce-free equilibrium point with $R_{0}>1$, it can be concluded that the divorce-free equilibrium point is 
Syamsir, Syamsuddin Toaha, Kasbawati Jurnal Matematika, Statistika $\mathcal{E}$ Komputasi

unstable. Meanwhile, the eigenvalue is related to the endemic equilibrium point of the divorce $\{-1.0196,-0.0687,-0.0200,-0.0310\}$. All eigenvalues are negative at the endemic equilibrium point of divorce at $R_{0}>1$, it can be concluded that the endemic equilibrium point of divorce is stable. The graphs of the values $M^{*}, S^{*}, D^{*}$ and $H^{*}$ are presented in Figure 5.1, Figure 5.2, Figure 5.3 and Figure 5.4.
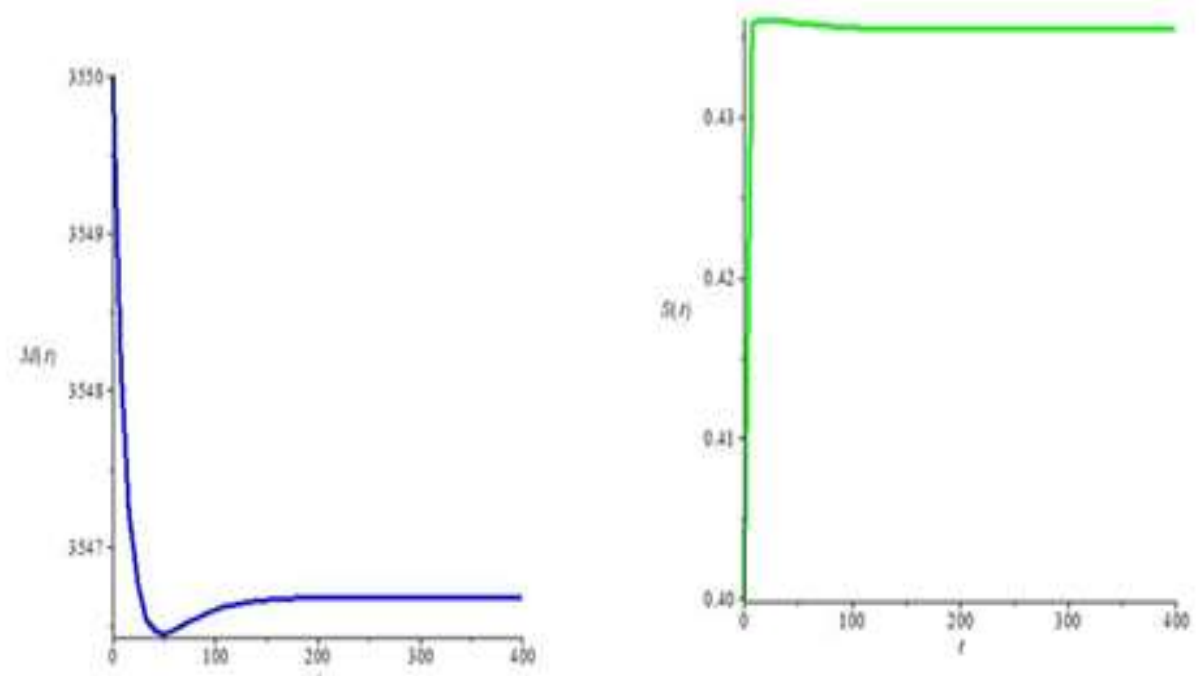

Figure 5.1.Proportion of humans who were married Figure 5.2. Proportion of humans who were at t for $R_{0}>1$ split bed when $\mathrm{t}$ for $R_{0}>1$
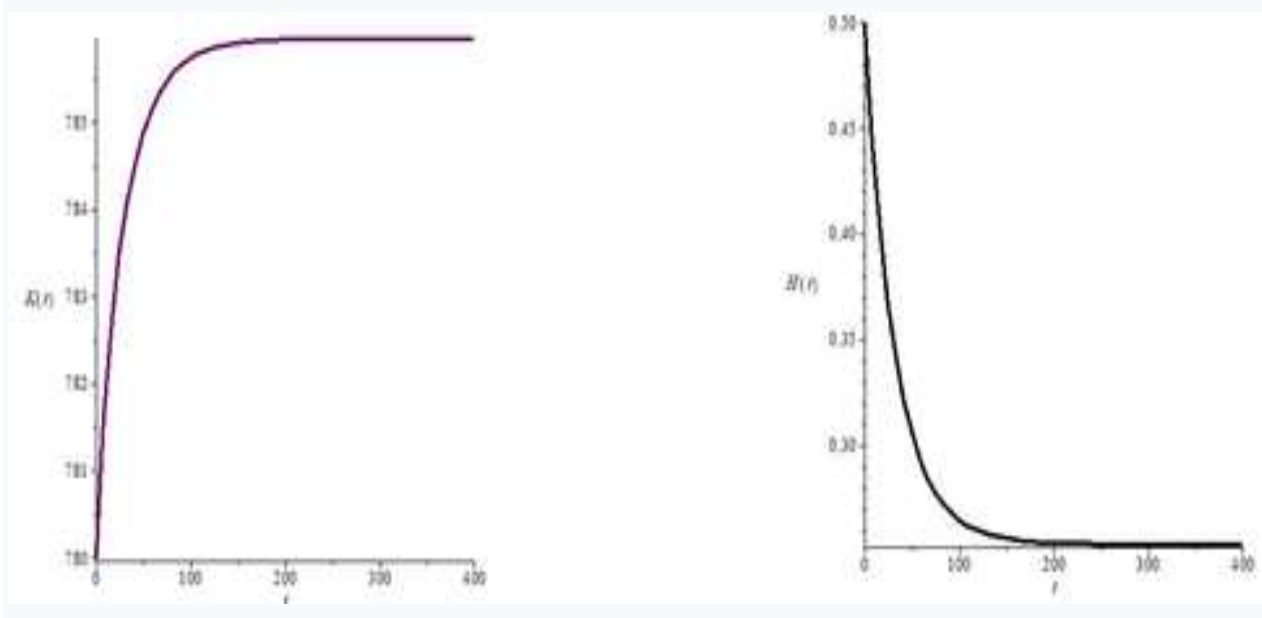

Figure 5.3. Proportion of people who were divorced Figure 5.4. Proportion of people who were 


\section{Syamsir, Syamsuddin Toaha, Kasbawati Jurnal Matematika, Statistika E Komputasi}

at $\mathrm{t}$ for $R_{0}>1$

were depresse or stressed at time $\mathrm{t}$ for $R_{0}>1$

Figure 5.1 shows that the value $M(t)$ lead to $M^{*}$ as long as the increments of t. Then in Figure 5.2, Figure 5.3 and Figure 5.4 it can be seen that the value $S(t), D(t)$ and $H(t)$ respectively leading to $S^{*}, D^{*}$ and $H^{*}$ as long as $t$ increments. In other words, Figure 5.1 to Figure 5.4 shows that $\lim _{t \rightarrow \infty}\left(M^{*}, S^{*}, D^{*}, H^{*}\right)=E^{*}$. So the equilibrium point $E^{*}$ is asymptotically stable. While Graph - a graph of value $M^{0}, S^{0}, D^{0}$ and $H^{0}$ are presented in Figure 5.5, Figure 5.6, Figure 5.7 and Figure 5.8.
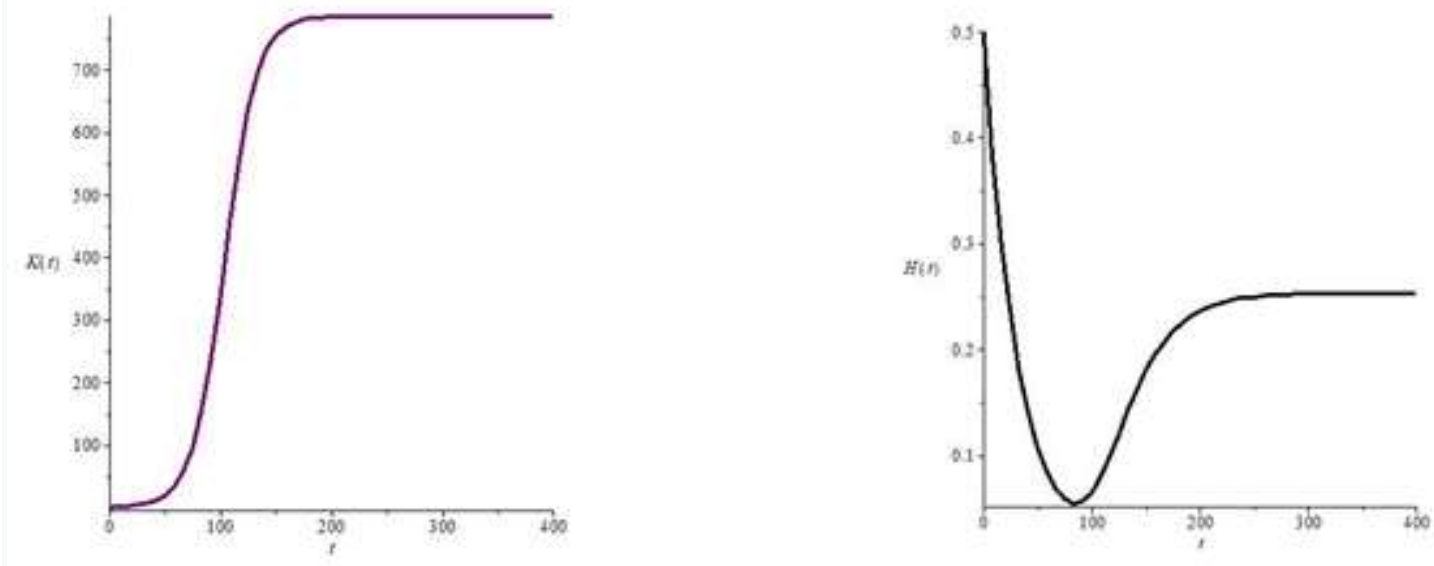

Figure 5.5. Proportion of people who were married Figure 5.6. Proportion of people who were at time t for $R_{0}>1$ separated from bed at time $\mathrm{t}$ for $R_{0}>1$
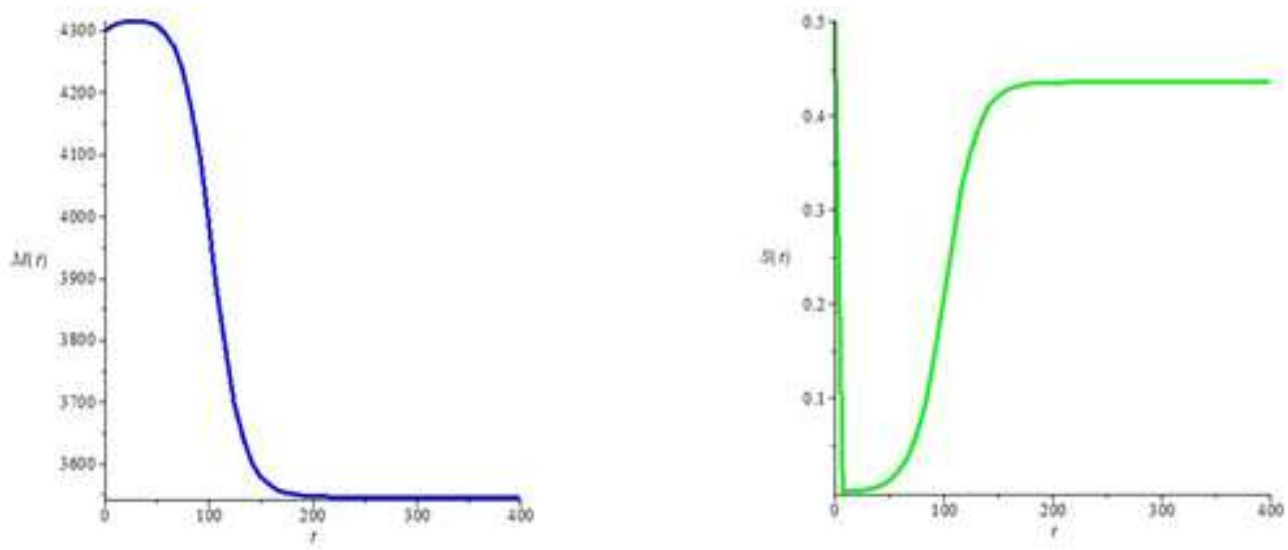

Figure 5.7. Proportion of people who were divorced Figure 5.8. Proportion of people who at time t for $R_{0}>1$ 


\section{Syamsir, Syamsuddin Toaha, Kasbawati Jurnal Matematika, Statistika \& Komputasi}

In Figure 5.5, it can be seen that the value of $M(t)$ does not go towards or away from $M^{0}$ as long as $t$ increases. Then in Figure 5.6, Figure 5.7 and Figure 5.8 it can be seen that the values of $S(t), D(t)$ and $H(t)$ also do not go to $S^{0}, D^{0}$ and $H^{0}$ respectively as long as $t$ increases. In other words, in Figures 5.5 to 5.8 it can be seen that $\lim _{t \rightarrow \infty}\left(M^{0}, S^{0}, D^{0}, H^{0}\right) \neq E^{0}$. So the equilibrium point $E^{0}$ is unstable.

\section{b. Simulation for $\boldsymbol{R}_{\mathbf{0}}<\mathbf{1}$}

The parameter values given when $R_{0}<1$ are $\mu=0.03, \beta=0.08, \rho=0.052, \gamma=0.00001, \delta=$ $0.00001, \varepsilon_{1}=0.99, \varepsilon_{2}=0.35, \varepsilon_{3}=0.001, \mathrm{P}=0.021, u_{1}=0.9999$, and $u_{2}=0$. With this parameter value, the divorce-free equilibrium point is obtained $E^{0}=\left(M^{0}, S^{0}, D^{0}, H^{0}\right)=$ $(4333,0,0,0)$, while the endemic equilibrium point does not exist as well as value $R_{0}=$ 0.9961843109 . The eigenvalues associated with the divorce-free equilibrium point are $\{-0.0300$, $-0.0310,-0.0012,-1.0195\}$. All e igenvalues are negative at the divorce-free equilibrium point at $R_{0}<1$, it can be concluded that the divorce-free equilibrium point is stable. The graphs of the values $M^{0}, S^{0}, D^{0}$ and $H^{0}$ are presented in Figure 5.9, Figure 5.10, Figure 5.11 and Figure 5.12.
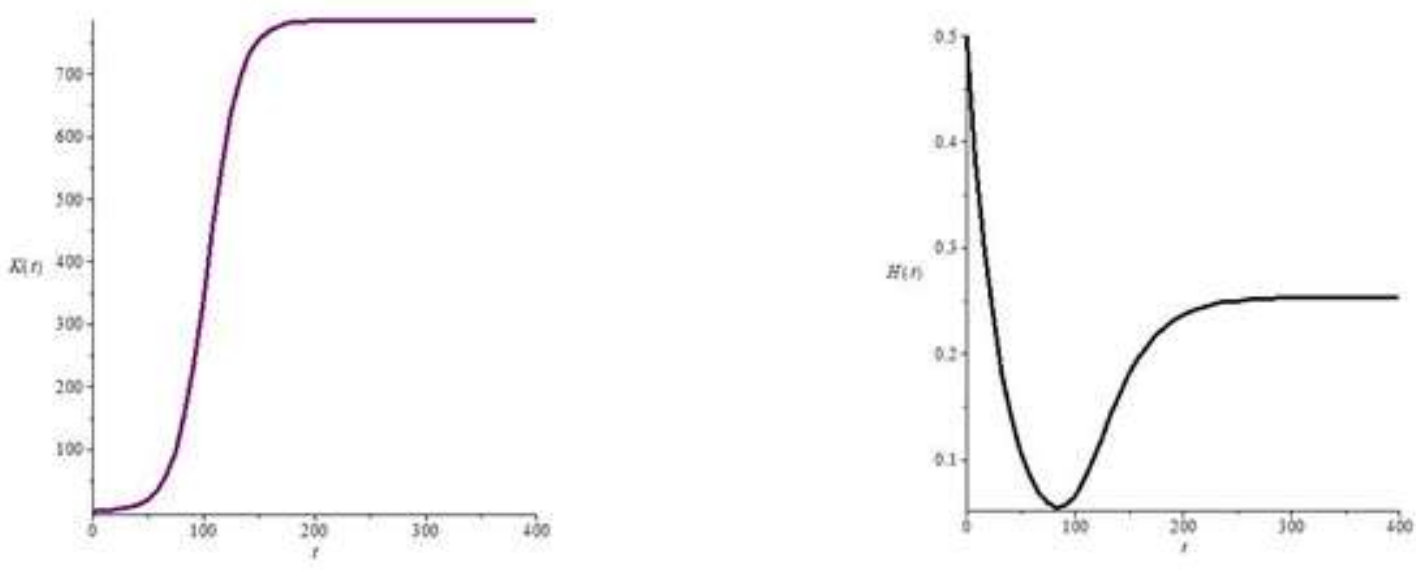

Figure 5.9. Proportion of people who were married Figure 5.10. Proportion of people who at $\mathrm{t}$ for $R_{0}<1$ were separated from bed at time $\mathrm{t}$ for $R_{0}<1$ 


\section{Syamsir, Syamsuddin Toaha, Kasbawati Jurnal Matematika, Statistika \& Komputasi}
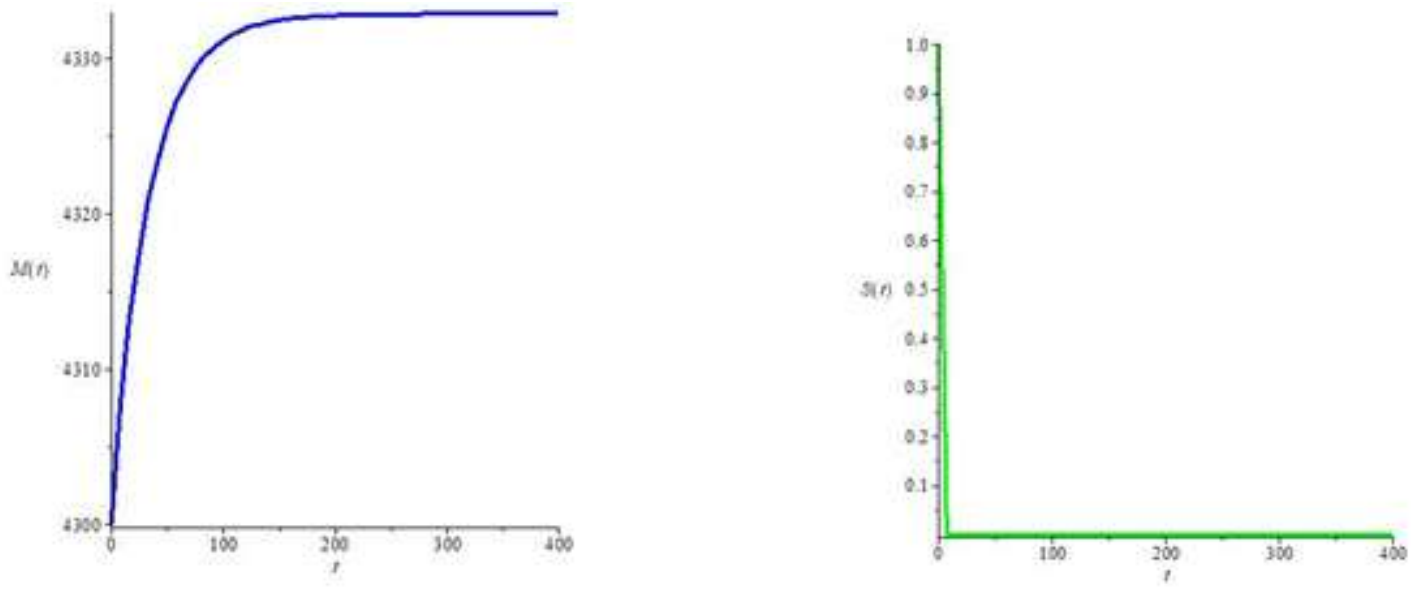

Figure 5.11. Proportion of people who were divorced Figure 12. Proportion of humans who at time $\mathrm{t}$ for $R_{0}<1$ were depressed or stressed at time $\mathrm{t}$ for $R_{0}<1$

In Figure 5.9 it can be seen that the value of $M(t)$ goes to $M^{0}$ as long as $t$ increases. Then in Figure 5.10, Figure 5.11 and Figure 5.12, it can be seen that the values of $S(t), D(t)$ and $H(t)$ go to $S^{0}, D^{0}$ and $H^{0}$ respectively as $t$ increases. In other words, in Figures 5.9 to 5.12 it can be seen that $\lim _{t \rightarrow \infty}\left(M^{0}, S^{0}, D^{0}, H^{0}\right)=E^{0}$. So the equilibrium point $E^{0}$ is stable for $R_{0}<1$.

\section{Conclusion}

The mathematical model of the dynamics of divorce has an equilibrium point of divorce-free and divorce. The analysis results from the model also obtained the basic reproduction number $\left(R_{0}\right)$. From the value of the basic reproduction number, it can be seen that whether all the eigenvalues associated with the divorce-free equilibrium point and the existence of divorce are all negative or not. There are several parameters that affect the value of $R_{0}$, namely the proportion of married people who are divorced ( $\rho$ ), the average interaction between people with married status and other individuals $(\beta)$, the chances of successful interactions between people with married status and other populations $(\mathrm{P})$, the proportion of individuals who have avoided divorce due to the presence of external parties (Judge) $\left(u_{2}\right)$ natural death rate $(\mu)$, rate of people returning to marriage status after separation $\left(\varepsilon_{2}\right)$ and the rate of people experiencing depression or stress after divorce $(\gamma)$.

When $R_{0}<1$, all eigenvalues associated with the divorce-free equilibrium point are negative. This means that the point of divorce-free equilibrium is stable. Whereas when $R_{0}>1$, there is one eigenvalue associated with a positive divorce-free equilibrium point and all eigenvalues associated with the equilibrium point of the divorce are all negative. 


\section{Syamsir, Syamsuddin Toaha, Kasbawati Jurnal Matematika, Statistika $\mathcal{E}$ Komputasi}

This means that the divorce-free equilibrium point is unstable and the equilibrium point of divorce is stable. From the results of this analysis and the model simulation performed using maple 18, it is shown that if the reproduction number is smaller than one, there will be no divorce. However, if the parameters $\rho, \beta, P$, and $u_{2}$ are increased and the parameter $\varepsilon_{2}$ is decreased, then the value of the reproduction number will be more than one and divorce will occur, in other words there will be a divorce epidemic so that individuals who divorce and interact with other populations will remain in the population.

\section{References}

[1] Achmad, Djumairi. S.H., 1990. Civil Law II. Semarang: Lecturer at the Faculty of Syari'ah IAIN Walisongo.

[2] Boyce, W. E. \& DiPrima, R. C., 2012. Elementary Differential Equations. 10th Edition penyunt. United States: John Wiley \& Sons.

[3] Braun, M., 1983. Differential Equations and Their Applications. Springer Verlag, New York.

[4] Driessche \& Watmough., 2002. Reproduction numbers and sub-threshold endemic equilibria for compartmental models of disease transmission. Mathematical Biosciences.

[5] Finizio, \& Ladas., 1988. Usual Differential Equations with Modern Applications. Erlangga: Jakarta.

[6] Gambrah PP, Abdul Samad A, \& Adzadu Y., 2018. Divorce Transmission Model International Journal of Statistics and Applied Mathematics.

[7] Gambrah P.P., \& Adzadu Y., 2018. Mathematical model of divorce epidemic in Ghana International Journal of Statistics and Applied Mathematics.

[8] Hartati. H, Toaha S \& Kasbawati., 2019. Stability analysis of SEISEIR-SEI modelling on the dynamics of spread dengue fever with vaccination and insecticide J. Phys.: Conf. Ser. 1341 062033. doi:10.1088/1742-6596/1341/6/062033.

[9] Law of the Republic of Indonesia Number 1 of 1974 concerning Marriage and Government Regulation Number 9 of 1975. Jakarta. 


\section{Syamsir, Syamsuddin Toaha, Kasbawati Jurnal Matematika, Statistika E Komputasi}

[10] Lenhart, S. \& Workman, J. T., 2007. Optimal Control Applied to Biological Models. London: Taylor \& Francis Group.

[11] Nurfitria P, Toaha S \& Kasbawati, 2020. Model Matematika VSEIR penyebaran Penyakit Antraks pada Populasi Hewan dengn Efek Vaksinasi dan Pengobatan, Vol.17,No.1,doi:10.20956/jmsk.v17i1.10050.

[12] Sulma, Toaha S. \& Kasbawati, 2020. Stability Analysis of Mathematical Models of Meningitis Transmission dynamics with the Effect of Vaccination, Campaign and Treatment, Vol.17,No.171-81,doi: 10.20956/jmsk.v\%vi\%oi.10031.

[13] Toaha S., Kusuma J, Khaeruddin \& Mawardi, 2014. Stability analysis and optimal harvesting policy of prey-predator model with stage structure for predator Applied Mathematical Sciences 8(159) 7923-7934.

[14] Toni B., 2014. Pontryagin's Minimum Principle Optimum Control. IPB Mathematics Department.

[15] Wiggins S., 2003. Introduction to Applied Nonlinear Dynamical Systems and Chaos, secon edition. California Institut Of Technology. 